\title{
The Psychotherapy Process Q-set from the perspective of the Italian research in psychotherapy: Commentary on a Paper by J. Stuart Ablon, Raymond A. Levy, and Lotte Smith-Hansen
}

\author{
Vittorio Lingiardi ${ }^{1}$, Laura Bonalume ${ }^{2}$, Antonello Colli ${ }^{3}$, \\ Daniela Gentile $^{1} \&$ Annalisa Tanzilli ${ }^{1}$
}

\begin{abstract}
In their review, Ablon, Levy, and Smith-Hansen (2011) showed that the Psychotherapy Process Q-set (PQS; Jones, 2000) has been applied to a large range of studies with different methods and aims, from Randomized Control Trials (RCT) to naturalistic studies and single-case designs. Focusing on our colleagues' work, we will highlight the contribution of the PQS to research in psychotherapy, not only in process-outcome studies, but also into the therapeutic action debates, the specific vs common factors discussion, and the insight $v s$ relation dialect. According to our studies, PQS has played the most relevant and innovative role in psychoanalysis. Ablon et al. showed how Jones left the clinical inheritance of his empirical method. One of PQS's strengths deals with the Q-sort methodology (Block, 1961; Stephenson, 1953) that enables both an empirical study of human subjectivity (McKnown \& Thomas, 1988) and the application of rigorous data analysis for single-case designs, such as the P-technique and time series analysis. PQS, as colleagues have shown, is useful in single-case designs that, despite their limitations in the generalization of the findings (Kazdin, 2002), capture the richness and complexity of the clinical dialogue and describe the uniqueness of the patient and therapist dyad and interaction structures.
\end{abstract}

\footnotetext{
${ }^{1}$ Sapienza University of Rome, Italy

${ }^{2}$ University of Milan-Bicocca, Italy

${ }^{3}$ University "Carlo Bo" of Urbino, Italy.

E-mail: vittorio.lingiardi@uniroma1.it
}

(Received 7 April 2011; Revised 15 May 2011; Accepted 22 October 2011) 
The comprehensive and detailed review with which Ablon, Levy, and Smith-Hansen (2011) described the PQS studies in the past 25 years demonstrates its widespread applicability and usefulness for a large range of process studies in psychotherapy.

Jones is regarded as a pioneer of the "fourth generation," as Wallerstein (2002) defined the researchers in psychotherapy who began to satisfy the requirements for submitting psychotherapy to empirical validation, focusing on process-outcome studies, "practiced as usual," and applying advanced tools to sample of transcripts or whole sessions (Lingiardi \& Dazzi, 2008). The "dodo bird verdict" decreed the so-called "equivalence paradox" in psychotherapy (Luborsky, Singer, \& Luborsky, 1975), according to which only common therapeutic factors promote the process of change; this paradox involves an important fault: It ignores that many technical and specific factors can predict the change. As Ablon et al. (2011) showed, the pantheoretical orientation of the Psychotherapy Process Q-set (PQS; Jones, 2000) enabled Jones to validate the hypothesis that "key processes" operate in treatment within different theoretical orientations; it also allowed researchers to indagate "what works for whom?" (Roth \& Fonagy, 2004). Jones recognized specific factors would not be very informative about "how" patients really improve. Comparing different schools of psychotherapy and studying the adherence to prototypical treatment (Ablon \& Jones, 1998, 1999, 2002, 2005; Ablon, Levy, \& Katzenstein, 2006) called into question the uniformity myth of patients (Kiesler, 1966) and underlined the importance of "tailoring" (Horwitz, Gabbard, \& Allen, 1996): Beyond theoretical orientations, what happens in clinical practice concerns much more than the patient's characteristics.

Hence, Jones went over the rigidity of the specific $v s$ non-specific dualism, outlining the role of each dyad of "interaction structures" and "specific processes" that Ablon et al. (2011) defined as "unique, ideographic and idiosyncratic" (p. 15). We agree with colleagues that any attempts in specifying a treatment process ideally conducted appear necessarily superficial and reductive. 
Focusing on Ablon et al.'s (2011) review, we will point out some PQS characteristics in order to demonstrate PQS's qualities, its versatility in studying treatment processes, and its clinical implications.

\section{PQS structural and methodological characteristics}

First, we want to comment on some PQS structural and methodological characteristics that enable its wide application in psychotherapy research and its clinical implications.

As already pointed out, PQS provides a pantheorical approach with a descriptive, transtheoretical and non-slang language that allows researchers to analyze transcripts with different theoretical orientations. Jones proposed a rigorous and empirical methodology, starting from a bottom-up approach (Westen, Novotny, \& Thompson-Brenner, 2004) that suggests that theory would result from empirical and naturalistic observations of phenomena. As Ablon et al. (2011) described, PQS items are anchored in observable and objective, verbal and nonverbal markers. This structure improves the "clinical inference," allows "guided" clinical evaluation, and increases its validity and inter-raters' reliability, as different studies have demonstrated. The new manual revision by the Ablon and Levy research group (2009) clarifies some uncertain descriptions and operationalizations; ${ }^{1}$ the electronic version facilitates and accelerates the scoring procedures. This rating procedure also increases the value of videotape coding, which facilitates a naturalistic observation of patient-therapist interactions and reduces biases from clinical inference.

Ablon et al. (2011) underlined the role of the entire hour as the unit of analysis, as a distinctive feature and methodological characteristic of PQS; indeed, it allows researchers to see "in vivo" what really happens in the patient-therapist interactions. Even if we believe in PQS validity in looking at a macro level of the treatment process and interactive and relational features, combining PQS coding with other mycroanalyitc measures could

\footnotetext{
${ }^{1}$ In the new version, item 1 , for example, describes not only the verbal factors, but also the non-verbal expressions of emotions.
} 
facilitate the observation of individual patient-therapist interactions during the global process. In this regard, the psychotherapy research literature suggests the importance and the utility of using synergistically macro or molar and micro or molecular levels of analysis (Heaton, Hill, \& Edward, 1995) in order to describe therapeutic impasses and the way patients and therapists co-construct dyadicaly their relationship (The Boston Change Process Study Group, 2010). An Italian in progress study, for example, has combined PQS analysis with the Collaborative Interactions Scale (CIS; Colli \& Lingiardi, 2009) in order to evaluate both the global features of the dyad interactions and, at a micro-level, therapeutic alliance ruptures and collaborative processes between patients and therapists during session (Colli, Trecca, \& Lingiardi, 2008).

Focusing on Levi, Ablon, Ackerman, \& Seybert (2008), Ablon et al. (2011) zeroed in on the limitations of some PQS items that have temporary and momentary characteristics in the clinical dialogue. ${ }^{2}$ Also in this case, ratings of unique and clinically relevant segmentations or episodes could facilitate the identification of point and/or waving phenomena of the interaction; it can also remedy data loss, concerning events coded by problematic items.

Finally, although Ablon et al. (2011) do not refer directly to it, the most important and innovative PQS methodological characteristic concerns the Qsort methodology (Block, 1961, 1978; Stephenson, 1953), which is regarded as one of the strengths of the Jones's instrument (Blatt, 2005; Fonagy, 2005; Hauser, 2005). The recovery of the Q-sort method has allowed the usefulness and applicability of PQS in process studies in the past 25 years. Q-sort has been "rediscovered" for measuring multiple psychological constructs as personality assessments (Shedler \& Westen, 1998; Westen \& Shedler; 1999; Westen, Shedler, \& Lingiardi, 2003), attachment processes (Block \& Kremen, 1996), identities and self-images (Hauser, Jacobson, Noam, \& Powers, 1983), coping and defense processes (Haan, 1977; Vaillant,

${ }^{2}$ In the Case of Amalia X, colleagues underlined the difficulties in some items' coding, as Q11 (Sexual feelings and experiences are discussed), Q12 (Silences occur during the hour), Q42 (Patient rejects therapist's comments and observations), and Q58 (Patient did not examine thoughts, reactions, or motivations related to his or her role in creating or perpetuating problems). 
1992), and peer and close relationships (Allen, Hauser, O'Connor, \& Bell, 2002). Q-sort offers a rigorous technique for the study of human subjectivity while maintaining the integrity of individual expression within a specific context (Colli \& Gazzillo, 2006; McKeown \& Thomas, 1988). Q-sort methodology in psychological assessment (Block, 1961, 1978; Hauser, 2005; Stephenson, 1953) enables researchers/judges to integrate clinical complexity with measurable purposes, assuming a forced normal items distribution, as Ablon et al. (2011) described. This method not only reduces raters' biases and the influence of response style, it also lends itself to single-case design research, in which the subject's experience is assessed at different times across the therapy process. The method can also be used for dynamic factor analysis, comparing multiple subjects, in order to describe process causal, instead of only correlational analysis (Ablon \& Jones, 1998, 1999, 2002, 2005; Block, 1961, 1978; McKnown \& Thomas, 1988). PQS therefore represents an ideal approach to the single-case studies in which the same patient-therapist dyad is examined multiple times during the therapeutic process, as Ablon et al. (2011) described in the cases of Mr. A, Mrs. C, Ms. M and Amalia X (Albani, Blaser, Jacobs, Jones, Thomä, \& Kächele, 2002; Jones, Ghannam, Nigg, \& Dyer, 1993; Levy et al., 2008; Porcerelli, Dauphin, Ablon, Leitman, \& Bambery, 2007). In other single-case designs, therapy processes from a specific treatment approach is compared with prototypes of ideal treatment, as in the cases of Beth and Maria (Katzenstein, 2007; Pole, Ablon, O`Connor, \& Weiss, 2002). In these singlecase studies, Ablon et al. (2011) show examples of different statistical analysis to PQS data: P-technique (Luborsky, 1953, 1995) is a version of repeated measures factor analysis to the patient-therapist dyad data in order to capture the interaction structures. Time series analysis (Gottman, 1981) is a technique for changing the evaluation along a time dimension. Abilities to measure "therapeutic processes" and unique and dyadic interaction structures involve multiple implications in clinical and therapeutic practices and in psychoanalysis research, where in the past 
single-case studies were analyzed by anecdotal reports (Ablon, 2005; Kächele, Schachter, \& Thöma, 2009; Levine, 1994; Lingiardi, 2006).

\section{PQS among research and practice: the clinical heredity of an empirical method}

Ablon et al. (2001) described the chronological and methodological evolution of PQS applications, taken into consideration the Randomized Control Trials (RCT) studies, for outcomes and processes and they investigated different treatment approaches and single-case studies to which they dedicated much more time, according to PQS's usefulness in this kind of research. Focusing on these research branches, we will comment on the relevant aspects, suggesting questions and propositions for future psychotherapy research.

\section{Group process and outcome research}

In the first part of review, Ablon et al. (2011) describe that Jones' belief at the beginning of his work with PQS was concerned with demonstrating that common or non-specific factors were not solely responsible for therapeutic change, but rather that distinct processes might operate differently in predicting outcomes depending on the patient and therapist characteristics, symptom severity, and phase of treatment. Hence, Jones' contribution arises from psychotherapy research requirements to formulate questions and responses about "therapeutic action" (Gabbard \& Westen, 2003) as a detailed set of goals, strategies, and techniques operating in the therapist and patient interactions and promoting change. PQS is based on the assumption that there are no ideal or universal treatments. Otherwise, we might give credence to two implicit and doubtful premises: a) interpersonal processes have a fixed and context-independent meaning and b) different treatment outcomes depend only on the ideal and "universal" process.

While Ablon et al. (2011) described the chronological and empirical evolution of PQS research from RCT studies about treatment outcomes and processes by comparing therapy between different treatment orientations 
and developing prototypes of ideal treatments for single-case studies, they also retraced implicitly the debate about "what works for whom" (Roth \& Fonagy, 2004) and the demand of "tailored psychotherapy" (Horwitz et al., 1996), focusing both on the patient's and therapist's characteristics and interaction features.

In this regard, in the process-outcome studies, mentioned by Ablon et al. (2011), PQS applications established that psychodynamic treatment for depression (Ablon \& Jones, 1998, 1999, 2002, 2005; Fonagy, 2006) and panic disorders (Ablon, Levy, \& Katzenstein, 2006; Levy \& Ablon, 2009; Kaztestein, Ablon, \& Levy, 2009) are empirically supported. Also, the PQS application also facilitated a description of treatment processes of patients with PTSD - Post Traumatic Stress Disorder (Jones, Cumming, \& Horowitz, 1988) and avoidant personality disorder (Porcerelli et al., 2007). To this end, our interest in future research is on developing prototypes for the treatment process of patients with different diagnoses and multiple types of controtransference (Tobin, 2006). We also hope to expand PQS processoutcome studies for patients with personality disorders, as Porcerelli et al. (2007) have already done.

Ablon et al. (2011) touched on studies about patients and therapist characteristics, particularly patients' emotional experiences and expressions (Coombs, Coleman, \& Jones, 2002) and reflective functioning (Karlsson \& Kermott, 2006) associated with treatment outcomes and processes. All of these PQS studies, detailed by colleagues, have not only contributed to the "what works for whom" debate (Roth \& Fonagy, 2004), but they have also noted the importance of treatment-specific/non-specific factors, positioning between Empirically Supported Treatment - EST vs Empirically Supported Relationship - ESR (Nathan \& Gorman, 1998; Norcross, 2011).

As we have discussed, Jones and PQS went over the diatribe, highlighting what happens in the clinical practice: Findings from studies of adherence to ideal treatment processes allow talking about "empirically supported change processes" (Ablon \& Jones, 1998, 2002; Ablon et al., 2006; Jones, Parke, \& Pulos, 1992; Jones \& Pulos, 1993), as specific "processes" affecting 
treatment outcomes. As Ablon et al. (2011) pointed out, studies that look beyond brand-name therapy and analyze therapy transcripts are much more informative (Ablon \& Jones, 1998, 2002). Studying treatments according to their brand names could be quite misleading. Wachtel (2010) noticed that PQS was not designed to detect the presence of the brand-name therapy "packages" that are the focus of the "EST" approach, but rather of very specific kinds of comments and behaviors operating in the actual process. As we know, beyond treatment brands and theoretical approaches, the "real" therapy process is much more different and heterogeneous, compared with an "ideal" prototype (Ablon \& Jones, 1998, 2002; Ablon et al., 2006). As Westen (Westen et al., 2004) highlighted, EST limitations concern the adherence to manualized treatments and the uniformity myth of patients, as if we could use the same treatment protocol -i.e., a gold standard- across patients with different diagnoses and in several phases of treatment. Shedler (2010) underlined that the "active ingredients" of therapy are not necessarily those presumed by the theory or treatment model. For this reason, Randomized Control Trials (RCT) that evaluate a therapy as a "package" do not necessarily provide support for PQS's theoretical premises or the specific interventions that derive from them. At the same time, PQS did not indulge in ESR proposals, which proclaim relational factors and denigrate the influence of technical and specific treatment factors.

Starting from these assumptions, the future of psychotherapy research with PQS should focus on the active ingredients of the treatment process, combining, as we have already stated, micro and macro analyses as CIS (Colli \& Lingiardi, 2009), as noted Psychotherapy Relationship Questionnaire-PRQ (Bradley, Heim, \& Westen, 2005), Countertransference Questionnaire-CTQ (Betan, Heim, Zittel, \& Westen, 2005), Working Alliance Inventory-WAI (Horvath \& Greenberg, 1989), Session Evaluation Questionnaire-SEQ (Stiles, Gordon, \& Lani, 2002).

It may be of great importance, for example, to deepen studies on therapeutic alliance and interaction structures, as shown by Price and Jones (1998). It might also be useful to study the association between 
process features and good therapeutic alliances and vice versa, the negative quality of collaborative processes between patients and therapists during sessions. Our recent study (Lingiardi, Colli, Gentile, \& Tanzilli, 2011) has examined specific and non-specific dimensions of the psychotherapy process, investigating the relationship between the therapeutic alliance, as measured by Working Alliance Inventory-Observer (Horvath \& Greenberg, 1989) and depth of elaboration during session, coded with the Depth Scale of Session Evaluation Questionnaire (Stiles \& Snow, 1984). The results are in line with findings by Price \& Jones (1998), Coombs et al. (2002), and Karlsson \& Kermott (2006).

Multi-method evaluations have the advantage of combining measures of multiple dimensions (therapeutic alliance, ruptures and repairs, transference and countertransference, therapist interventions, and defenses, etc.). The cross-checking of different treatments and dyadic process variables may be the main way to study outcomes and therapeutic relations.

\section{PQS, single cases and clinical practices}

In this review, Ablon et al. (2011) gives more time to single-case studies by highlighting that "PQS represents an ideal instrument for such research" (p. 26). We agree about the relevance of single-case studies, which provide an essential view of treatment not captured by group and aggregated data. The usefulness of single-case research designs, despite limitations in the generalization of the results, has been underlined by many researchers (Gottman, 1973; Jones, 1993a, Kächele et al., 2009; Kazdin, 2002; Lingiardi, 2006). The methodology of intensive single-case studies may capture the ideographic nature of the patient and therapist dyad and their specific interaction structures (Ablon \& Jones, 2005; Jones \& Windholz; 1990; Porcerelli et al., 2007). Single-case designs enable accurate descriptions of how changes happen over time and which ingredients are active in the therapeutic process (Albani et al., 2002; Jones et al., 1993; Katzenstein, 2007; Pole \& Jones, 1998). 
Combining Randomized Control Trials (RCT) and single-case studies, Jones and PQS have provided to psychotherapy research with an empirical and valid method with various clinical implications. They have also paved the way for innovative considerations on therapeutic action, insight $v s$ relation dialectic, and interaction structures (Gabbard \& Westen 2003).

The single-case design has been useful, in particular, for measuring the construct of "interaction structure" developed with a bottom-up approach, starting from multiple data coded with PQS on session transcripts. Although Ablon et al. (2011) did not underline this concept, their "interaction structure" allows us to go over the dialectic insight vs relation. PQS's applications to single cases, described by colleagues, demonstrates empirically that insights and relations cannot be separated. In the case of Mrs. C (Ablon \& Jones, 2005), for example, the patient's psychological experience of self developed inside the relational context with the therapist, who tried continuously to understand the patient's mind through mutual interaction and acceptance of the patient's self-exploration.

There are no therapeutically ideal processes. Individual dyads of therapists and patients are characterized by repetitive interaction structures that represent both subjects' functioning. In the cases of Mr. A and Ms. M (Jones et al., 1993; Porcerelli et al., 2007), colleagues have shown the development and transformation of these structures in promoting therapeutic changes. The PQS's efforts in measuring empirically and effectively single-case dynamics and phenomena not only enhance research in psychotherapy, but they also positively contribute to the development of research in psychoanalysis based on anecdotal reports before Jones' studies (Kächele et al., 2009; Lingiardi, 2006). Jones widely wondered about the psychoanalytical need for experimental and quantitative studies using reliable and practice-oriented methodologies (Jones, 1993b). Research in psychoanalysis is only possible with rigorous instruments applied to the transcripts of sessions that capture the richness and complexity of therapeutic processes. The contributions of the PQS, as a robust instrument for single-case phenomena, to psychoanalysis research have been widely 
appreciated (Fonagy, 2002; Kächele \& Thöma, 2001; Leuzinger-Bohleber \& Target, 2002; Roth, Fonagy 2004). Although colleagues have highlighted the pantheorical approach of PQS, the therapies they described are essentially psychoanalysis-oriented.

Finally, another important theoretical clue to Jones' approach concerns the application of PQS to "individual case formulation," according to patient characteristics and resources (Jones, 1998; Pole et al., 2002). Even if Ablon et al. (2011) did not focus on this aspect, Jones suggested an assessment approach that takes into account the patient's capabilities to collaborate with the therapist in order to plan the treatment (Jones, 2000). It assumes that both psychopathological characteristics and psychological resources may be assessed more broadly by using what occurs during the actual treatment process (Jones, 1998). Only after some sessions, according to the process information, can the therapist decide which treatment orientation might be reliable for a specific patient to promote a good outcome. This assessment approach, needing only a few sessions, has the advantage of linking patient evaluation and treatment. Focusing on the nature of the ongoing treatment is essential for a more comprehensive, effective, and fruitful assessment of the patient's psychological functioning. It should be also investigated with the application of single-case design, as an ideal methodological approach.

In the past 20 years, several research and clinical psychodynamicoriented groups have tried to develop reliable, valid, and outcome-oriented instruments for diagnostic purposes. In fact, PQS is one of the selected tools by Wallerstein (2005), together with Shedler-Westen Assessment Procedure200 (SWAP-200; Westen, Shedler, \& Lingiardi, 2003), the Operationalized Psychodynamic Diagnosis (OPD; OPD Task Force, 2001), and the Karolinska Psychodynamic Profile (KAPP; Weinryb, Rössel, \& Asberg, 1991a, 1991b), and others, which created the Psychodynamic Diagnostic Manual (PDM; PDM Task Force, 2006, p. 75).

In our opinion, other future purposes in psychotherapy research might deal with the application of PQS to the definition of prototypical processes 
for different personality diagnoses and to the analyses of initial phases of treatment and assessment processes in order to investigate interaction structures that characterize therapeutic processes and promote outcomes.

\section{Conclusions}

As we have pointed out, the review by Ablon et al. (2011) allows us to retrace the theoretical and empirical evolution of PQS and the main debate developments in the history of psychotherapy and psychoanalysis research: Randomized Control Trials (RCT) and single-case studies; EST and ESR; specific and common factors; therapeutic actions, and interaction structures.

The comprehensive and consecutive reviews about PQS studies, from RCT to single cases, demonstrate that group and single-case studies are both methodological strategies a researcher should know and use, according to actual research characteristics and needs (Lingiardi, 2006). As Kazdin (2002) stated, the variability and richness in clinical research has implications for the method to use. It is not always possible to apply an ideal methodology. Operationalization of clinical constructs is one of the most difficult aspects of research in psychotherapy. Jones, as prime mover, succeeded in beginning multiple works about rigorous and clinical practiceoriented instruments.

Beyond diatribes about specific vs non-specific factors and insight $v s$ relation, the PQS answers the pluralism of therapeutic orientations with the theory of "therapeutic action" in order to capture what changes (goals of treatment) and which strategies promote changes (treatment techniques).

As Ablon et al. (2011) stated that we should not describe an individual process, but "therapeutic processes" or better "borrowed processes" (Ablon et al., 2011, p. 44). "None of this is surprising," according to Fonagy (2005), who commented, "What was remarkable was that such everyday clinical wisdom could be demonstrated in an empirical study. This is the magic of the PQS [...] It taps the range of therapy techniques in a way directly relevant to one's work as a clinician" (p. 581). 
As colleagues have stated, it is our hope that future research in psychotherapy, during its theoretical, methodological, and empirical evolution, will be conducted with open-minded perspectives as it is a bridge between practice and research.

\section{References}

Ablon, J. S. (2005). Reply to Blatt and Fonagy. Journal of the American Psychoanalytic Association, 53, 591-595.

Ablon, J. S., \& Jones, E. E. (1998). How expert clinicians' prototypes of an ideal treatment correlate with outcome in psychodynamic and cognitive-behavioral therapy. Psychotherapy Research, 8, 71-83.

Ablon, J. S., \& Jones, E. E. (1999). Psychotherapy process in the National Institute of Mental Health Treatment of Depression Collaborative Research Program. Journal of Consulting and Clinical Psychology, 679(1), 64-75.

Ablon, J. S., \& Jones, E. E. (2002). Validity of Controlled Clinical Trials of Psychotherapy: Findings from the NIMH Collaborative Study. The American Journal of Psychiatry, 159(5), 775-783.

Ablon, J. S., \& Jones, E. E. (2005). On analytic process. Journal of the American Psychoanalytic Association, 53, 541-568.

Ablon, J. S., \& Levy, R. (2009). Psychotherapy Process Q-Set. Coding Manual Revised. Unpublished manuscript, University of California, Berkeley.

Ablon, J. S., Levy, R., \& Katzenstein, T. (2006). Beyond brand names of psychotherapy: Identifying empirically supported change processes. Psychotherapy: Theory, Research, Practice, Training, 43(2), 216-231.

Ablon, J. S. Levy, R. A., \& Smith-Hansen, L. (2011). The Contributions of the Psychotherapy Process Q-set to Psychotherapy Research. Research in Psychotherapy: Psychopathology, Process and Outcome, 14(2), 14-48.

Albani, C., Blaser, G., Jacobs, U., Jones, E. E., Thomä, H., \& Kächele, H. (2002). Amalia X's psychoanalytic therapy in the light of Jones's Psychotherapy Process Q-Sort. In M. Leuzinger-Bohleber \& M. Target (Eds.), Outcomes of Psychoanalytic Treatments. Perspectives for Therapists and Researchers (pp. 294-302). London/Philadelphia: Whurr Publishers. 
Allen, J. P., Hauser, S. T., O’Connor, T. G., \& Bell, K. L. (2002). Prediction of peerrated adult hostility from autonomy struggles in adolescent-family interactions. Development \& Psychopathology, 14, 123-137.

Betan, E., Heim, A. K., Zittel, C., \& Westen, D. (2005). Countertransference phenomena and personality pathology in clinical practice: An empirical investigation. American Journal of Psychiatry, 162, 890-898.

Blatt, S. J. (2005). Commentary on Ablon and Jones. Journal of American Psychoanalytic Association, 53, 569-578.

Block, J. (1961). The Q-Sort Method in the Personality Assessment and Psychiatric Research. Springfield: Charles C. Thomas.

Block, J. (1978). The Q-Sort Method in the Personality Assessment and Psychiatric Research. Palo Alto, CA: Consulting Psychologists Press.

Block, J., \& Kremen, A. (1996). IQ and ego-resiliency: Conceptual and empirical connections and separateness. Journal of Personality \& Social Psychology, 70, 349-361.

Bradley, R., Heim, A. K., \& Westen, D. (2005). Transference patterns in the psychotherapy of personality disorders: Empirical investigation. The British Journal of Psychiatry, 186, 342-349.

Colli, A., \& Gazzillo, F. (2006). Due strumenti per la valutazione del processo terapeutico: le Analytic Process Scales e lo Psychotherapy Process Q-set [Two instruments for evaluation of psychotherapeutic process: The Analytic Process Scales and the Psychotherapy Process Q-set]. In N. Dazzi., V. Lingiardi \& A. Colli (Eds.), La ricerca in psicoterapia. Modelli e Strumenti (pp. 677-689). Milano: Raffaello Cortina Editore.

Colli, A., \& Lingiardi, V. (2009). The Collaborative Interactions Scale: A new transcript-based method for the assessment of therapeutic alliance ruptures and resolutions in psychotherapy. Psychotherapy Research, 19(6), 718-734.

Colli, A., Trecca, M. I., \& Lingiardi, V. (2008, Settembre). Un'analisi fattoriale dinamica delle interazioni collaborative tra paziente e terapeuta [A dynamic factorial analysis of the collaborative interactions between patient and therapist]. Relazione presentata al VII Congresso Nazionale SPR, Modena.

Coombs, M. M., Coleman, D., \& Jones, E. E. (2002). Working with feelings: The importance of emotion in both cognitive-behavioral and interpersonal therapy in the NIMH Treatment of Depression Collaborative Research Program. Psychotherapy: Theory, Research, Practice, Training, 39(3), 233-244. 
Fonagy, P. (2002). An Open Door Review of Outcome Studies in Psychoanalysis (2nd ed.). New York: International Psychoanalytic Association.

Fonagy, P. (2005). In praise of simplicity: Commentary on Ablon and Jones. Journal of the American Psychoanalytic Association, 53(2), 579-589.

Fonagy, P. (2006). Psicoterapie psicodinamiche evidence-based [Psychodynamic psychotherapy evidence-based]. In PDM Task Force (Eds.), PDM. Manuale Diagnostico Psicodinamico (pp. 659-725). Milano: Raffaello Cortina Editore.

Gabbard, G. O., \& Westen, D. (2003). Rethinking therapeutic action. International Journal of Psychoanalysis, 84, 823-841.

Gottman, J. M. (1973). $N$-of-one and $N$-of-two research in psychotherapy. Psychological Bulletin, 80, 93-105.

Gottman, J. M. (1981). Time Series Analysis. New York: Cambridge University Press.

Haan, N. (1977). Coping and Defending. New York: Academic Press.

Hauser, S. T. (2005). The legacy of Enrico Jones. Journal of American Psychoanalytic Association, 53(2), 535-539.

Hauser, S. T., Jacobson, A., Noam, G., \& Powers, S. (1983). Ego development and self-image complexity in early adolescence: Longitudinal studies of diabetic and psychiatric patients. Archives of General Psychiatry. 40(3), 325-332.

Heaton, K. J., Hill, C. E., \& Edwards, L. A. (1995). Comparing molecular and molar methods of judging therapist techniques. Psychotherapy Research, 5(5), 141-153.

Horvath, A. O., \& Greenberg, L. S. (1989). Development and validation of the Working Alliance Inventory. Journal of Counseling Psychology, 36, 223-233.

Horwitz, L. M., Gabbard, G. O., \& Allen, J. T. (1996). Borderline personality disorder: Tailoring the psychotherapy to the patients. Arlington, VA: American Psychiatric Publishing.

Jones, E. E. (1985). Manual for the Psychotherapy Process Q-Set. Unpublished manuscript, University of California, Berkeley, CA.

Jones, E. E. (1993a). Introduction to special section: Single-case research in psychotherapy. Journal of Consulting and Clinical Psychology, 61(3), 371-372.

Jones, E. E. (1993b). How will psychoanalysis study itself? Journal of the American Psychoanalytic Association, 41, 91-108.

Jones, E. E. (1998). Depression: Intervention as assessment. In J. Barron (Eds.), Making Diagnosis Meaningful: Enhancing Evaluation and Treatment of 
Psychological Disorders (pp. 267-297). Washington: American

Psychological Association.

Jones, E. E. (2000). Therapeutic action: A guide to psychoanalytic therapy. Northvale, NJ: Aronson.

Jones, E. E., Cumming, J. D., \& Horowitz, M. J. (1988). Another look at the nonspecific hypothesis of therapeutic effectiveness. Journal of Consulting and Clinical Psychology, 56, 48-55.

Jones, E. E., Ghannam, J., Nigg, J. T., \& Dyer, J. F. P. (1993). A paradigm for single-case research: The time series study of a long-term psychotherapy for depression. In Journal of Consulting and Clinical Psychology, 61, 381-394.

Jones, E. E., Parke, L. A. \& Pulos, S. M. (1992). How therapy is conducted in the private consulting room: A multivariate description of brief dynamic treatments. Psychotherapy Research, 2, 16-30.

Jones, E. E., \& Pulos, S. M. (1993). Comparing the process in psychodynamic and cognitive-behavioral therapies. Journal of Consulting and Clinical Psychology, 61(2), 306-316.

Jones, E. E., \& Windholz, M. (1990). The psychoanalytic case study: Toward a method for systematic inquiry. Journal of the American Psychoanalytic Association, 38(4), 985-1016.

Kächele, H., Schachter, J., \& Thöma, H. (Eds.). (2009). From Psychoanalytic Narrative to Empirical Single Case Research: Implications for Psychoanalytic Practice. New York, NY: Routledge.

Kächele, H., \& Thomä, H. (2001). La ricerca in psicoanalisi. Lo studio del caso clinico [Research in psychoanalysis. The clinical case study]. Tr. it. Quattroventi, Urbino 2003.

Karlsson, R., \& Kermott, A. (2006). Reflective-functioning during the process in brief psychotherapies. Psychotherapy: Theory, Research, Practice, Training, 43(1), 65-84.

Katzenstein, T. (2007). Empirical validation of change processes in long-term psychodynamic psychotherapy: The bidirectional effects of clinician-patient interaction. Dissertation Abstracts International: Section B: The Sciences and Engineering, 67(8-B), pp. 4712.

Katzenstein, T., Ablon, J. S., \& Levy, R. A. (2009). A naturalistic treatment for panic disorder. In R. Levy \& J. S. Ablon (Eds.), Handbook of Evidence-Based 
Psychodynamic Psychotherapy: Bridging the Gap between Science and Practice (pp. 45-65). Totowa, NJ, US: Humana Press.

Kazdin, A. E. (2002). Overview of research design issues in clinical psychology. In

P.C. Kendall, J. Butcher \& G. Holmbeck (Eds.), Handbook of Research Methods in Clinical Psychology. New York: John Wiley and Sons.

Leuzinger-Bohleber, M., \& Target, M. (Eds.). (2002). Outcomes of psychoanalytic treatment. London/Philadelphia: Whurr.

Levine, H. D. (1994). The analyst's participation in the analytic process. The International Journal of Psychoanalysis, 75, 665-676.

Levy, R., \& Ablon, S. J. (Eds.). (2009). Handbook of Evidence-Based Psychodynamic Psychotherapy: Bridging the Gap between Science and Practice. New York: Human Press.

Levy, R. A., Ablon, J. S., Ackerman, J. A., \& Seybert, C. (2008). The Psychotherapy Process Q-set and Amalia X, session 152. In C. Albani, J. S. Ablon, R. A. Levy, W. Mertens \& H. Kächele (Eds.), Der "Psychotherapie Prozess Q-Set" von Enrico E. Jones. Deutsche Version und Anwendungen (pp. 7-41). Ulm: Ulmer Textbank.

Lingiardi, V. (2006). La ricerca single-case [Single-case research]. In N. Dazzi, V. Lingiardi \& A. Colli (Eds.), La ricerca in psicoterapia. Modelli e Strumenti (pp. 123147). Milano: Raffaello Cortina.

Lingiardi, V., Colli, A., Gentile, D., \& Tanzilli, A. (2011). Exploration of Session Process: Relationship to Depth and Alliance. Psychotherapy, 48(4), 391-400.

Lingiardi, V., \& Dazzi, N. (2008). Introduzione all'edizione italiana [Introduction to Italian edition]. In E. E. Jones (2000), L'azione terapeutica (pp. VII-XVIII). Milano: Raffaello Cortina.

Luborsky, L. (1953). Intraindividual repetitive measurements (P-technique) in understanding psychotherapeutic change. In E. Mowrer (Eds.), Psychotherapy, Theory and Research (pp. 389-413). New York: Ronald Press.

Luborsky, L. (1995). The first trial of the P technique in psychotherapy research - A still lively legacy. Journal of Consulting and Clinical Psychology, 63, 6-14.

Luborsky, L., Singer, B., \& Luborsky, L. (1975). Comparative studies of psychotherapies. Archives of General Psychiatry, 32, 995-1008.

McKeown, B., \& Thomas, D. (1988). Q-Methodolgy. Newbury Park, CA: Sage.

Nathan, P. E. \& Gorman, J. M. (Eds). (1998). Treatments that work. New York: Oxford University Press. 
Norcross, J. C. (Ed.). (2011). Psychotherapy Relationships that Work (2nd ed.). New York: Oxford University Press.

OPD TAsk Force (2001). Operationalized Psychodynamic Diagnostics: Foundations and Manual. Seattle: Hogrefe \& Huber.

PDM TASK Force (2006). PDM. Manuale Diagnostico Psicodinamico [PDM. Psychodynamic Diagnostic Manual] Tr. it. Raffaello Cortina, Milano 2008.

Pole, N., Ablon, J. S., O'Connor, L., \& Weiss, J. (2002). Ideal control mastery technique correlates with change in a single case. Psychotherapy: Theory, Research, Practice, Training, 39(1), 88-96.

Pole, N., \& Jones, E. E. (1998). The talking cure revisited: Content analyses of a two-year psychodynamic psychotherapy. Psychotherapy Research, 8(2), 171-189.

Porcerelli, J. H., Dauphin, V. B., Ablon, J. S., Leitman, S., \& Bambery, M. (2007). Psychoanalysis with avoidant personality disorder: A systematic case study. Psychotherapy: Theory, Research, Practice, Training, 44(1), 1-13.

Price, P. B., \& Jones, E. E. (1998). Examining the alliance using the Psychotherapy Process Q-Set. Psychotherapy: Theory, Research, Practice, Training, 35(3), 392404.

Roth, A., \& Fonagy, P. (2004). What Works for Whom? A Critical Review of Psychotherapy Research (2nd ed.). New York: Guilford Press.

Shedler, J. (2010). The Efficacy of Psychodynamic Psychotherapy. American Psychologist, 65(2), 98-109.

Shedler, J., \& Westen, D. (1998). Refining the measure of Axis II: A Q-Sort procedure for assessing personality pathology. Assessment, 5, 333-353.

Stephenson, W. (1953). The study of behavior: Q-technique and its methodology. Chicago: University of Chicago Press.

Stiles, W. B., Gordon, L. E., \& Lani, J. A. (2002). Session evaluation and the Session Evaluation Questionnaire. In G .S. Tryon (Ed.), Counseling based on process research: Applying what we know (pp. 325-343). Boston, MA: Allyn \& Bacon.

Stiles, W. B., \& Snow, J. S. (1984a). Counseling session impact as viewed by novice counselors and their clients. Journal of Counseling Psychology, 31, 3-12.

The Boston Change Process Study Group (2010). Change in Psychotherapy. A Unifying Paradigm. New York: Norton \& Company. 
Tobin, M. J. (2006). Countertransference and therapeutic interaction: An exploratory study. Dissertation Abstracts International: Section B: The Sciences and Engineering, 67(4-B), pp. 2247.

Vaillant, G. E. (Ed.). (1992). Empirical Studies of Ego Mechanisms of Defense. Washington, DC: American Psychiatric Press.

Wachtel, P. L. (2010). Beyond "ESTs". Problematic Assumptions in the Pursuit of Evidence-Based Practice. Psychoanalytic Psychology, 27(3), 251-272.

Wallerstein, R. S. (2002b). Psychoanalytic therapy research: An overview. The American Psychoanalyst, 36, 10-13.

Wallerstein, R. S. (2005). Outcome research. In E. S. Person, A. M. Cooper \& G. O. Gabbard (Eds.), Textbook of Psychoanalysis (pp. 301-315). Arlington, VA: American Psychiatric Publishing Inc.

Weinryb, R. M., Rössel, R. J., \& Asberg, M. (1991a). The Karolinska Psychodynamic Profile, I: Validity and dimensionality. Acta Psychiatrica Scandinavica, 83, 64-72.

Weinryb, R. M., Rössel, R. J., \& Asberg, M. (1991b). The Karolinska Psychodynamic Profile, II: Interdisciplinary and cross-cultural reliability. Acta Psychiatrica Scandinavica, 83, 73-76.

Westen, D., Novotny, C. M., \& Thompson-Brenner, H. (2004). The empirical status of empirically supported psychotherapies: Assumptions, findings, and reporting in controlled clinical trials. Psychological Bulletin, 130, 631-663.

Westen, D., \& Shedler, J. (1999a). Revising and assessing Axis II, part 1: Developing a clinically and empirically valid assessment method. American Journal of Psychiatry, 156, 258-272.

Westen, D., Shedler, J., \& Lingiardi, V. (2003). La valutazione della personalità con la SWAP-200 [The Personality Assessment with SWAP-200]. Milano: Raffaello Cortina. 